\title{
DO GOVERNO AUTÁRQUICO Ã SOCIEDADE TECNOCRÁTICA: AS CONTRADIÇÕES DO CORPORATIVISMO E O CRESCIMENTO DA AUTONOMIA BUROCRÁTICA NA ESPANHA DEPOIS DA GUERRA CIVIL*
}

Ian M. Japlin ***

\section{Introdução}

Estudos recentes sobre o Estado voltaram a algumas proposições clássicas - muitas vezes weberianas - a fim de superar as limitações impostas pelo marxismo ortodoxo e pela teoria política liberal. Ambos enfocam o Estado como árbitro de conflitos sociais, enfatizando, respectivamente, a dominação ou o consenso. Em ambas as abordagens o Estado é reduzido, tanto empírica quanto conceitualmente, a uma mera arena, na qual vários grupos em competição e/ou em conflito lutam pela dominação. Os teóricos liberais discutem em torno da legitimidade e do consenso e analisam a forma pela qual diversos atores defendem e negociam "regras de jogo" institucionalmente consisten$t^{2}{ }^{2}$. Entrementes nota-se entre os marxistas um interesse renovado pela crise do Estado, o que levou alguns a retomar às abordagens ortodoxas ${ }^{3}$. Enquanto muitos autores marxistas reconhecem (ao menos implicitamente) que as estruturas do Estado coincidem com os respectivos modos de produção, que são componentes constitutivos de configurações classistas dentro desta estrutura, alguns começaram a discutir em torno da autonomia relativa do Estado em relação ao controle específico de uma classe dominante. Mas esta discussão em geral tem sido inconclusiva e tem levado a definiçð̄es funcionalistas do Estado

\footnotetext{
${ }^{1}$ Gostaria de agradecer a Clive Ashworth, Bill Canak, Peter Evans e Dennis Smith pelos seus comentários críticos e sugestões.

${ }^{2}$ Cf. C. Tilly (ed.), The Building of States in Western Europe.

${ }^{3}$ Cf. Gold, D; Lo, C. Y.-H.; Wright, E.O., "Recent developments in Marxist themes of the
} 
ou a uma antropomorfização do mesmo na forma de luta de classes. A tenta. tiva de Block de resguardar grande parte deste argumento contra armadilhas teleológicas fornece uma visão ampla da dinâmica das diferentes pressões de classe sobre o aparato estatal e com isto abre caminho para conceber o Estado como uma entidade parcialmente autônoma.

Estudos com maior fundamentação empírica, como os de Trimberger ${ }^{4}$ e Skocpol ${ }^{5}$, apresentam argumentos semelhantes. A primeira preocupa-se com o crescimento de um aparelho burocrático estatal relativamente autônomo e uma burocracia estatal com dinamismo próprio. Para Trimberger o Estado e a burocracia militar não são meros instrumentos do grupo economicamente do. minante e se distanciaram ou separaram deste grupo e dos meios de produção da sociedade. Esta separação faz com que não se prestem a satisfazer aos interesses que os grupos dominantes atribuem ao Estado. Em seu estudo da revolução Skocpol vê o Estado como uma macroestrutura que é basicamente "um conjunto de organizações administrativas, políticas e militares, encabeçado e coordenado de forma mais ou menos adequada por uma autoridade executiva. Qualquer Estado, em primeiro lugar e fundamentalmente, extrai recursos da sociedade e os utitiliza para criar e manter organizações coercitivas e administrativas" 6 . Partindo deste esquema mais ou menos weberiano, ela centraliza sua análise numa distinção entre os determinantes estruturais internos a uma sociedade e o contexto internacional desta mesma sociedade. Da mesma forma que Trimberger, ela pensa que o Estado não pode ser reduzido a forças e conflitos sócio-econômicos, mas constitui uma entidade potencialmente independente, cujos recursos estão depositados nas organizaçбes administrativas e coercitivas.

Partindo de uma idéia semelhante sobre as limitações das teorias liberalpluralistas e marxistas sobre o Estado, Stepan defende um grau de autonomia do Estado que é hegeliano quanto à sua inspiração e corporativista em suas manifestações. Utilizando o conceito de estatismo orgânico, analisa como os Estados na América Latina se mantiveram intervencionistas e orientados para a estruturação de representação de interesses e buscaram sua justificação normativa para o governo muito mais na hegemonia do que na coerção?

A preocupação central de Trimberger, Skocpol e Stepan é a autonomia do Estado, com atenção especial para o papel das burocracias. Evidentemente

Capitalist State", in Monthly Review, 1975, Oct./Nov.; Jessop, B., "Recent Theories of the Capitalist State", in Cambridge Journal of Economics, 1977.

${ }^{4}$ Trimberger, E.K., Revolution from Above, 1978.

${ }^{5}$ Skocpol, T., States and Social Revolutions, 1979.

${ }^{6}$ Ibid, p. 29.

${ }^{7}$ Stepan, A., The State and Society: Peru in Comparative Perspective, 1978. 
Do Governo Autárquico à Sociedade Tecnocrática ...

interessa saber por que e em que condições burocracias estatais se transformam em entidades relativamente autônomas; e embora a resposta de Trimberger pode ser encontrada na existência de uma burguesia fraca e/ou na dependência de interesses estrangeiros, é difícil generalizar a partir de exemplos como o do Egito e do Peru, como no caso dela.

$O$ estudo que segue pretende examinar algumas das posições citadas em torno da autonomia do Estado, examinando o caso da Espanha posterior à guerra civil. Se procurará demonstrar sobretudo como o crescimento de uma burocracia estatal autônoma durante o período de Franco foi a conseqüência lógica de uma rara configuração estrutural da sociedade espanhola, que abriu um vácuo político, bem como da tendência centralizadora, a marca pessoal imposta ao governo autoritário pelo ditador.

Depois da guerra civil (1936-39) Franco procurou reconstruir e reintegrar a sociedade espanhola, criando uma estrutura autoritária corporativa ${ }^{8}$ em torno de interesses essencialmente agrário-burocráticos. Ele reestruturou a burocracia estatal através de uma combinação de pessoal militar, falangistas (o partido neofascista, do qual esperava legitimação ideológica) e cidadãos "leais". 0 operariado foi reprimido, apesar de que fossem criadas organizações sindicais horizontais não-representativas para "dirigir" de forma mais sistemática as atividades da força trabalhadora. O Estado franquista era, por isso, um

"regime autoritário estável..., um sistema político com pluralismo limitado, não responsável; sem uma elaborada ideologia orientadora (mas com uma mentalidade distintiva); sem uma mobilização política intensiva ou extensiva, onde um líder exerce o poder dentro de limites formais mal-definidos, mas na verdade bastante previsíveis"9.

Trata-se claramente de uma tentativa de despolitização maciça, com a rotinização do carisma de Franco como um dos fatores legitimadores do regime. Organizado e comandado por dirigentes estatais, mas supervisionado e dirigido em última instância pelo próprio Franco, esta marca pessoal que distinguia o corporativismo autoritário perdurou até o final da década de 1950 . Neste momento ficou finalmente claro que esta junção de governo autárquico e isolacionismo estava conduzindo à bancarrota econômica e no começo

${ }^{8} \mathrm{O}$ conceito de corporativismo usado aqui segue muito de perto a abordagem de Strinati, representando arranjos institucionais organizados pelo Estado para criar as condiçōes políticas para a intervenção econômica. Cf. "State and industrial relations", in C. Crouch, State and Economy in Contemporary Capitalism (London, 1979).

${ }^{9}$ Linz, citado em Car, R; Fusi, J.P., Spain, Dictatorship to Democracy, 1979, p. 47. 
da década de 1960 a Espanha começou a dar força ao neo-capitalismo - ainda sob a tutela de Franco - e a alimentar uma ideologia tecnocrática. $\mathrm{O}$ papel das diferentes elites dominantes, a consolidação do isolamento diplomático e, por fim, a forte liderança e controle exercidos pelo próprio Franco, contribuíram cada um para estabelecer a peculiaridade do caso espanhol. Cada um des. ses fatores será examinado a seguir a fim de estabelecer, em primeiro lugar, seu funcionamento e sua eficiência como partes constitutivas da autonomia do Estado e, em segundo lugar, sua relação com as configurações estruturais em mudança, que mediaram as relações entre classes dominantes e subalternas.

2. A reitegração da Espanha pós-guerra civil sob uma ideologia burocrático-agrária centralizada

A elite nacional que existia, quando começou a guerra civil, era um estrato dominante heterogêneo, composto de diferentes grupos da classe superior. A ideologia do franquismo que se cristalizou durante e depois da guerra constituía um apelo natural à disposição "conservadora" e tradicional do clero, dos militares e dos elementos agrários/financeiros que formavam este grupo. Estes eram os grupos que se sentiram mais ameaçados pelo governo da Frente Popular anterior à guerra civil e que em função disso apoiaram e ajudaram a sustentar o levante militar de 1936.

$\mathrm{O}$ legado das décadas anteriores à guerra é tal que se torna difícil falar em equilíbrio de forças na Espanha deste período. Da mesma forma é problemático falar de uma sociedade espanhola unificada e integrada. Antes da guerra o desenvolvimento industrial e comercial tinha afastado temporariamente 0 nordeste da Espanha do resto do país. Mas a agitação política das classes subalternas nestas áreas tinha afastado aquela que muitos viam como a única verdadeira "burguesia industrial" de seus objetivos separatistas, para transformar a Catalunha em uma região plenamente industrializada. Apesar de que a Catalunha e, em menor grau, a região basca e a área em torno de Valência estivessem começando a apresentar muitas das características estruturais de uma sociedade industrial - uma classe trabalhadora proletarizada e uma crescente classe média comercial -, apesar disso, elas continuavam a ser parte constitutiva de uma nação, na qual interesses pré-industriais ainda eram muito fortes e que ainda estava imersa no sistema de valores do catolicismo. Industiralização, secularização, urbanização e migração eram fenômenos evidentes, mas a gran- 
de maioria da população continuava ligada à agricultura ${ }^{10}$. Assim, o traço mais marcante da Espanha deste período era sua heterogeneidade.

O sucesso militar da classe dominante conservadora durante a guerra civil mostra a sua elasticidade como grupo uniforme, quando se tratava de assuntos nacionais. Ele também sugere que a evolução do Estado espanhol no futuro imediato deveria refletir um equilibrio de forças, no qual interesses agrários e comerciais apareceriam com destaque. A situação da Espanha pósrevolucionária era, por isso, semelhante a da Alemanha no século XIX após o fracasso das revoluções de 1848. Basicamente se tinha uma

"classe comercial e industrial que é muito fácil e dependente para tomar o poder e governar por sua própria conta, e que por isso se lança nos braços da aristocracia agrária e da burocracia imperial, trocando o direito de governar pelo direito de fazer dinheiro" 11 .

As diferenças no caso espanhol consistiam no desenvolvimento de uma burocracia autônoma a partir do início do século $\mathrm{XX}^{12}$ e o desejo de uma classe comercial/industrial periférica em trocar o poder nacional não só por dinheiro, mas também por poder regional (isto é, por um Estado catalão semiautônomo, no caso da burguesia catalã). Estes dois aspectos são importantes na medida em que eles determinam o caráter distintivo da Espanha pós-guerra civil e que por isso tiveram um impacto sobre as políticas subseqüentes, a organização institucional do Estado e a composição de classes. A seguir discutiremos a importância destes dois aspectos bem como dos aspectos citados anteriormente.

Autonomia burocrática e industrialização periférica eram dois fatores que surgiram durante o século XIX e que tomaram formas mais extremas com o desenvolvimento industrial que se verificou em certas regiōes no decorrer do século XX. Os dois fatores se tornaram problemáticos, porque determinaram uma situação estrutural em que as diferenças urbano-rurais normais (como as encontramos na maioria das sociedades industriais) assumiam formas regionalmente diferenctadas, onde as áreas industriais periféricas (no caso, as regiões

${ }^{10}$ A população ativa em 1940 distribuía-se em $50,52 \%$ na agricultura, $22,13 \%$ na indústria e $27,35 \%$ nos serviços. Cf. R. Tamames, Introducción a la Economia Española (Madrid, 1967).

${ }^{11}$ Moore Jr., Barrington, Social Origins of Dictatorship and Democracy (Harmondsworth, 1967), p. 437.

${ }^{12} \mathrm{~S}$. Giner, "The structure of Spanish society and the process of modernization", in Iberian Studies, 2/1972, p. 63. 
catalã e basca) apresentavam as características "urbanas" do continuum, enquando o restante do país, ainda dominado por uma sociedade agrária pré-industrial, mantinha a maioria das características rurais. O desenvolvimento de um sentimento nacionalista entre catalães e bascos, que podiam recorrer a uma língua que se distingue do espanhol e a uma tradição étnico-cultural diferente da de Castela, apenas complicou o quadro. Os dirigentes estatais, localizados em Madri ou originários de Castela, naturalmente resistiram e rejeitaram a expansão do nacionalismo periférico que era incentivado por tais grupos industriais.

A heterogeneidade do Estado espanhol anterior à guerra civil transformou-se assim em um problema para os dirigentes estatais. A ausência de uma ideologia nacional unificada e a existência de numerosas posturas políticas regionais em conflito (tanto como radicalismo proletário quanto como nacionalismo de origem comercial) tornou o arranjo político cada vez mais difícil. 0 fato de que estes interesses em competição tinham sua origem em diferenças materiais muito bem definidas entre os vários grupos (isto é, entre industriais, proletários, camponeses, latifundiários financistas) aumentava o problema. Cada um perseguia objetivos que estavam em acordo com seus próprios interesses e com um background sócio-econômico diferente. A guerra civil representou, portanto, uma crise de hegemonia e o problema para Franco e os conservadores depois da guerra residia na reintegração.

Em muitas sociedades o desenvolvimento industrial nacional foi o resultado da ascensão de grupos comerciais e industriais à custa de interesses préindustriais, com o conseqüente equilíbrio de forças tendendo significativamente em favor dos primeiros. Neste sentido costuma aparecer uma ideologia claramente definida e em geral uniforme, para influir e determinar a política administrativa, do que resulta uma integração funcional ${ }^{13}$ como dimensão relevante para o processo de transformação planejada. Tal situação é muito clara sob condições de tecnologia altamente desenvolvida, já que, como diz Cohen, "...elas facilitam o controle por parte do Estado ou de outras organizações sobre uma ampla gama de atividades sociais: incluem-se aí não só os meios de comunicação, mas também os de coerção" 13 . Integração funcional transforma-se, por isso, em elemento muito importante da administração política. Sempre haverá áreas que apresentarão um certo grau de autonomia (subculturas esotéricas, por exemplo); da mesma forma possíveis conflitos entre setores institucionais do sistema social são inevitáveis. Mas no caso da Es-

${ }^{13}$ P. Cohen, Modern Social Theory (London, 1968), pp. 155-56. Integração é vista aqui como um componente importante no management de processos sócio-políticos em uma sociedade e evita a mudança traumática.

${ }^{14}$ Ibid. 
panha estes aspectos assumiram proporções problemáticas em função do fato de que as crises classista-culturais e lingüísticas não resolvidas desembocaram em clivagens que acabaram tendo sua expressão na guerra civil.

A emergência de um setor industrial no início do século XX, e o processo de mudança a ele associado, conduziria - pensavam muitos - a uma integração funcional da população numa comunidade industrial nacional. Mas as manifestações da Espanha "invertebrada"15 continuaram a entravar o desenvolvimento de um Estado espanhol razoavelmente unificado em torno de políticas de desenvolvimento industrial nacional. A força dos grupos agrários, financeiros e burocráticos após o sucesso de Franco na guerra civil sugerem que o processo de reintegração representaria provavelmente uma tentativa de satisfazer os interesses destes grupos. A política do regime de Franco, ao defender valores conservadores, agrários e rurais em detrimento de valores industriais renovadores, foi uma expressão de tais interesses ${ }^{16}$. Apesar de que a tendência da política oficial durante a primeira década posterior à guerra fosse semelhante a outras ideologias fascistas típicas (como as afirmaçסes da Falange de que "nós transformaremos a Espanha num país de pequenos proprietários" 17, é mais correto enxergá-la como uma tentativa em construir proprietários"1 7 como uma instituição que expressasse interesses comensuráveis com aqueles grupos que eram predominantemente pré-industriais, burocráticos e conservadores - em outras palavras: os mais poderosos do momento ${ }^{18}$ - bem como uma simples expressão da visão de Franco sobre a Espanha.

O papel de Franco em influir nas operações políticas, remanejando gabinetes em operações muitas vezes pouco transparentes, e como determinante único de orientações políticas, não pode ser subestimado. Além de ter montado um esquema institucionalizado para pôr em prática seus programas, cabialhe a palavra final na maioria dos assuntos importantes. É claramente incorreto enxergá-lo como simples executor de iniciativas burocráticas - e neste sentido a burocracia só era autônoma na medida em que Franco o permitia. É este caráter personalizado do franquismo que distingue a Espanha de outros regimes burocrafico-autoritários ${ }^{19}$.

${ }^{15} \mathrm{~J}$. Ortega y Gasset, Invertebrate Spain (London, 1937).

${ }^{16}$ J. Esteban, "The economic policy of Francoism: an interpretation", in P. Preston Spain in Crisis (Hassocks, 1976), pp. 84-89.

${ }^{18} \mathrm{C}$. Moya Valganon, "Las élites económicas y el desarrollo español", in M. Iribarne, J. Fuertes, S. del C. Urbano, La España de los años 70 (Madrid, 1972), pp. 515-582.

Cf. outros dados sobre outros exemplos em G. O'Donnell, "Reflection on the Pattern of Change in the Bureaucratic-Authoritarian State", in Latin American Research Review, $13 / 1978$. 
Ao adotar uma postura que se pode chamar de agrário-burocrática, o Estado se alinhava ideologicamente com grupos e interesses que foram gradualmente emergindo durante o século XIX sob a tutela dos Moderados (o partido da direita). A igreja continuava a ser invocada para servir de legitima. ção (a guerra civil era vista pela direita como uma cruzada cristã contra os terrores do marxismo), enquanto, por outro lado, o apoio do exército (com sua possibilidade de coagir a população) tornou a participação das massas menos problemática do que ela fora nos governos parlamentares anteriores à guerra civil. Ao edificar as bases do poder sobre estes grupos, foram inevitavelmente excluídos aqueles, cujo apoio a tais instituiçōes tradicionais fora duvidoso as classes comercial e industrial - bem como aqueles que se opunham sistema. ticamente - as classes proletárias das cidades. A evolução do Estado nos anos seguintes está, por isso, muito bem caracterizada, quando Esteban descreve a ideologia oficial como constituindo-se de

"totalitarismo, antiliberalismo, subordinação da economia a fins políticos, preferência por valores agrários e rurais em detrimento de valores industriais e urbanos, e a ênfase constante no novo modo de vida, o Estado Novo, a Revolução Nacional" 20 .

O Estado franquista posterior à guerra civil pode assim ser claramente visto como um aparato político, de caráter totalitário, que procurou satisfazer, ainda que com independência, os interesses conservadores dos grupos agrário-burocráticos e financeiros da sociedade. Assim ele favorecia aqueles grupos, cujo poder não havia sido seriamente diminuído desde o começo do século XIX e dos quais muitos até se tinham fortalecido em função de mudanças estruturais parciais. Interesses industriais não podiam, a longo prazo, obter apoio entre tais grupos, mas durante o período inicial da consolidação hegemônica a busca de estabilidade resultou na aquiecência da burguesia periférica à estrutura dominante burocrático-agrária, e agora também militar. A incorporação de interesses pré-industriais à política do Estado franquista mostra que não se pode minimizar a continuidade do poder de tais grupos. Isto fica por demais evidente, quando se leva em consideração o caso dos latifundiários andaluzes.

A hegemonia local dos latifundistas se manteve firme durante a década de 1930, apesar das repetidas tentativas feitas pelo governo nacional para diminuir sua posição. Os latifundistas da Andaluzia e da Estremadura foram capazes de mobilizar e obter o apoio dos pequenos proprietários e arrendatários do sul contra a execução da proposta de reforma agrária da Segunda Repúbli-

${ }^{20}$ J. Esteban, op. cit., p. 85. 
ca. Isto é significativo, quando se leva em consideração que muitos dos propósitos desta reforma, como a garantia de posse e dos arrendamentos de longo prazo, teriam sido muito favoráveis aos pequenos proprietários e aos arrendatários. Mesmo assim estes se opuseram à proposta e apoiaram o grupo que mais perderia com as mudanças sugeridas ${ }^{21}$. Ainda mais que com a ausência de apoio institucional por parte do governo central deveria supor-se que os latifundiários recorressem cada vez mais a mecanismos espúrios de dominação na área local. Tais relações de dominação eram mantidas na esfera política através de uma combinação de caciquismo com um aparelho de intimidação e de barganha política em relação aos círculos de governo local e nacional. Economicamente seu controle sobre a terra e sobre as possibilidades de emprego no setor bem como sua influência sobre a estrutura do mercado garantiu a continuidade de sua dominação sobre a infra-estrutura das áreas rurais ${ }^{22}$.

A ausência de um forte e dinâmico setor comercial e industrial a nível nacional teve efeitos muito grandes sobre a evolução imediata da sociedade espanhola pós-guerra. Nas décadas anteriores à guerra civil muita gente pensava que a burguesia catalã relativamente desenvolvida poderia cumprir este papel nacional. Mas apesar de sua vontade em ajudar a desenvolver a estrutura sócioeconômica que interessava aos detentores de capital industrial, deve-se lembrar que eles constituíam uma classe essencialmente conservadora ${ }^{23}$. A elite industrial e financeira basca já havia demonstrado sua posição ideológica, ao identificar-se intimamente com a elite agrário-burocrática em Madri ${ }^{24}$. Como resultado auando os catalães perderam o apoio das classes inferiores nas primeiras décadas do século XX, relutaram em continuar com seus esforços separatistas, que os colocariam em oposição aos outros grupos conservadores, cen-

\footnotetext{
${ }^{21} \mathrm{P}$. Carrion, Los Latifundios en España (Madrid, 1932), cap. XII.

${ }^{22}$ C. Moya Valsanon, op. cit., pp. 516-543.
}

${ }^{23}$ Este é um ponto importante, que muitas vezes não é considerado. A burguesia catalã não foi o grupo politicamente ativo que se empenhasse em mudar a sociedade e em resistir contra os interesses opressivos de um governo dominado pelo latifúndio. Pelo contrário, ela compartilhava muitos dos sentimentos conservadores com as elites mais "tradicionais", mais ou menos da mesma forma que os comerciantes de Manchester durante o século XIX na Iñglaterra. Cf. A. Jutglar, Ideologias y clases en la España Contemporánea (Madrid, 1969), em especial cap. 5.

${ }^{24} \mathrm{O}$ nacionalismo basco apareceu mais tarde e recebeu adesão sobretudo entre as classes médias e os camponeses. Seu ímpeto inicial tinha sua origem no desejo de resguardar os valores sociais e o arcabouço moral da vida rural; assim adotou uma atitude defensva em relação à industrialização. Como resultado, a elite industrial basca nunca foi realmente ativa ou promotora do nacionalismo nesta área, tendendo pelo contrário para uma aproximação com os outros grupos das classes dominantes no restante da Espanha. Cf. The Basques (Minority Rights Group, London, 1971). 
tralistas, de Madri. Eles sentiram a necessidade de algum tipo de acordo, mesmo que pouco rígido com estes últimos grupos, se as classes inferiores não mais apoiassem seu próprio fervor nacionalista. $O$ rápido crescimento e a po. pularidade do anarco-sindicalismo demonstravam que a classe operária tinha, ao menos no momento, pouco interesse em apoiar seus sentimentos separatis. tas.

Ao colocar em xeque as aspirações nacionalistas dos catalães, a politização e o conseqüente radicalismo do proletariado urbano serviram para entravar o processo de desenvolvimento da industrialização nacional - ao menos temporariamente. Um certo grau de "suspeição" em relação aos capitalistas também existiu entre os dirigentes estatais em Madri nesta época. Isto se devia em parte à sua longa associação ao separatismo - um sentimento que causou hostilidade entre os centralistas em Madri. Aos seus olhos "capitalista" também sempre significara "liberal", e liberais no passado tinham atacado, como em outros países, todas aquelas instituições que eram consideradas importantes pela sociedade espanhola tradicional - sobretudo a igreja, a monarquia e a aristocracia. $O$ fato de que capitalismo significava desenvolvimento industrial constituiía uma outra afronta à sensibilidade conservadora, na medida em que tal processo envolvia uma grande reestruturação da sociedade e das relações sociais e, portanto, iria minar seu próprio status e sua posição. Além disso abriria as "comportas" à violência e ao radicalismo das classes inferiores, como os industriais de Barcelona haviam sentido na própria carne! Tal atitude dificilmente poderia ter levado a um crescimento industrial extensivo na Espanha, e portanto ao desejo - e em parte à necessidade - de a burguesia cataIã procurar uma evolução independente em relação ao restante da Espanha, dominada por Castela ${ }^{25}$. No entanto, a ala esquerda da Segunda República, apesar de concessões aos catalães em relação à autonomia, também encorajou, em função de sua postura política, a organização proletária. Em certo sentido isso acelerou o recuo por parte da burguesia catalã em relação ao separatismo e levou-a a identificar-se cada vez mais com os industriais e financistas conservadores bascos que haviam criado vínculos estreitos com o governo central.

A modernização espanhola girou assim em torno da configuração diversificada dos grupos desta classe dominante tenuamente agregada. As forças sociais se haviam polarizado, mas não de maneira que pudesse ter mudado a sorte das mudanças e do crescimento esperado pela classe industrial. Em lugar de uma aliança proletária-burguesa que pudesse ter pressionado os tradicionais grupos agrários que dominavam a política nacional - uma situação que ocorreu muitas vezes nas fases intermediárias do desenvolvimento latino-america-

${ }^{25}$ Havia um sentimento crescente que identificava o resto da Espanha como parasita econômico da Catalunha, frustrando seu desenvolvimento. 
no durante a segunda metade do século XIX -, o aumento do radicalismo das classes inferiores forçou a burguesia a aliar-se politicamente aos grupos agrários e financeiros do resto da Espanha ${ }^{26}$. Na verdade a burguesia continuou a encorajar a industrialização, mas tratava-se de um processo que era limitado por um aparelho político que era apoiado, e em certo sentido sustentado, pela elite agrário-burocrática ${ }^{27}$. Como resultado, parece que os grupos empresariais mais ativos - fortes sobretudo no nordeste, mas que também existiam em todo o resto do país - em vez de empunharem a bandeira contra o tradicionalismo e o latifúndio, fizeram uma aliança, e subordinaram seus interesses de longo prazo, a forças econômicas que - consciente ou não da situação - representavam o maior risco para a estagnação econômica a longo prazo ${ }^{28}$.

$\mathrm{O}$ legado da heterogeneidade continuou a afetar a década posterior à guerra civil. $\mathrm{O}$ dilema do período era que, para satisfazer às necessidades do crescimento econômico, era necessário pôr em prática uma série de mudanças na estrutura sócio-econômica. Tal política, segundo o pensamento conservador, minaria a estrutura básica da sociedade sobre a qual o crescimento deveria basear-se. Na sua opinião tratava-se de uma simples escolha entre duas políticas: estabilidade sem crescimento (uma sociedade construída sobre valores "rurais") ou crescimento sem estabilidade (fazendo concessões aos interesses de longo prazo dos grupos industriais). O resultado foi um compromisso, que no entanto tendia muito mais para a estabilidade e a manutenção de uma sociedade com um desenvolvimento industrial planejado pelo centro ${ }^{29}$. De forma semelhante à política que procurava restringir o radicalismo potencial das classes inferiores e prevenir o surgimento de uma oposição política organizada, o período posterior à guerra (até 1957) mostrou que se tentava conter os impulsos sócio-econômicos para a industrialização - em especial os efeitos democratizantes que tal processo teria sobre uma classe proletária em expansão.

Especialmente o aparelho criado por Franco para estimular a tão necessária recuperação foi formulado nos termos de um Estado corporativista. Impresso numa "moldura quase-tradicional" e utilizando, mas não dependendo da retórica ideológica falangista, foram desenvolvidos os seguintes instrumentos de governo autárquico.

${ }^{26}$ R. M. Glassman, "The limiting social and structural conditions of Latin American modernization", in Social Research, 1974.

${ }^{27} \mathrm{~K}$. Medhurst, Government in Spain (Oxford, 1973), cap. 2.

${ }^{28}$ Sobre política econômica e a implementação de mudanças econômicas cf. M. Roman, The limits of economic growth in Spain (Pracger, 1961).

${ }^{29} \mathrm{~K}$. Medhurst, op. cit., cap. 3 . 
O Instituto Nacional de Indústria (INI) foi organizado em setembro de 1941 como instrumento para promover novos empreendimentos que eram definidos como de "interesse nacional"' Basicamente um a grande holding públi$\mathrm{ca}$, foi planejado como um aparelho destinado a incentivar uma industrialização em áreas onde o capital privado de outra forma não se aventuraria, e a possibilitar baixas taxas de juros, incentivos fiscais e taxas de câmbio favoráveis (vinculadas a quotas de matérias-primas) ${ }^{30}$

Além disso a indústria foi regulamentada pela Lei de Proteção à Indústria Nacional (1939), que possibilitou ao Estado liberar o desenvolvimento industrial, dando poder efetivo para bloquear a entrada e/ou a expansão de competidores nacionais ou estrangeiros "desfävorecidos". Afora o inevitável favoritismo que acompanha qualuquer empreendimento público, o que esta lei fez foi aumentar a responsabilidade oficial pela ineficiência. Com pouco incentivo para racionalizar ou diversificar a produção, as indústrias existentes apenas mantiveram a produtividade dentro de um ambiente artificial. Livres da competição externa (seguida de grandes restrições às importações), havia poucos incentivos para promover mudanças ou melhorias na qualidade da produção.

Este aparelho de reconstrução era uma necessidade dentro do isolamento crescente a que estava exposta a Espanha na década de 1930, mas já era menos necessário na década de 1950. Baklanoff afirma:

"Em torno de 1850 - com a reconstrução quase concluída e as sanções econômicas das Nações Unidas revogadas - a Espanha poderia ter optado por uma estratégia de desenvolvimento orientada para fora. A simultânea recuperação econômica da Europa e o subseqüente estabelecimento de um amplo sistema multilateral e liberalizado de comércio, e de formas de pagamento, teria oportunizado à Espanha a participação nesta economia regional em expansão. Em vez de direcionar os recursos nacionais para um avanço relativo via maior especialização e intercâmbio internacional, a Espanha continuou seu caminho autônoma, até a crise de julho de 1959',31 .

$\mathrm{O}$ regime franquista destes anos configurou-se em torno de grupos que tentavam uma reintegração através de uma forma que acomodaria interesses conservadores (incluindo os dos grupos industriais conservadores). Diante da

${ }^{30} \mathrm{Cf}$. Baklanoff, E. N. The Economic Transformation of Spain and Portugal, 1978, pp. 15-16.

${ }^{31}$ Op. cit., p. 18. 
tarefa de réconstrução, juntamente com a tentativa de integração sócio-econômica de elementos até então díspares, todo o aparelho de controle econômico e de repressão política existente concentrou-se sobretudo em dois pontos. Um era o de conter a alegada ameaça de desordem proletária. $\mathrm{O}$ outro se referia à política governamental de firmar a auto-suficiência econômica nacional. Este último é mais conhecido pelo nome autárquico ${ }^{32}$. Mas as instituições sócio-econômicas e políticas criadas no início da década de 1940, apesar de representarem uma tentativa sistemática para criar uma estrutura que facilitasse a convivência política das classes superiores, eram internamente instáveis. Em vez de integrar todos os grupos burgueses com as demais elites, elas só criaram contradições entre eles. Ao tentarem limitar o desenvolvimento industrial e ao negarem qualquer concessão aos sentimentos separatistas (faziam-se agora menos concessð̃es ao nacionalismo catalão doque no período imediatamente anterior à guerra), era inevitável que clivagens tradicionais aparecessem novamente. Como conseqüência, não foi possível enfrentar adequadamente a crise de acumulação que se tornava aguda com a guerra civil. Estas contradições se acentuaram na década de 1950, quando houve um considerável desenvolvimento econômico no setor industiral, o qual aumentou a incompatibilidade entre os interesses materiais dos industriais e a estrutura política destinada a controlá-los ${ }^{33}$. Além disso, em vez de erradicar a desordem proletária, o regime na realidade a promoveu através do alto grau de exploração da classe operária durante as décadas de 1940/50, a qual foi desembocando gradativamente em greves e manifestações que foram assumindo cada vez mais uma conotação política ${ }^{34}$.

Em essência os modos básicos de produção - especialmente nas áreas rurais - permaneceram sem mudança desde as décadas anteriores à guerra civil. Durante a década de 1940 a produção caiu aos níveis anteriores à guerra, a estagnação dominou a economia e parecia que havia pouco desenvolvimento tecnológico e pouca inovação industrial. Na verdade estes eram evitados, na medida em que ameaçavam a estrutura das relações e a grande preocupação com a estabilidade ${ }^{35}$. Os projetos de reforma agrária dos republicanos foram modificados ou engavetados ou então diretamente descartados. Fazendas da Andaluzia que haviam sido expropriadas antes ou durante a guerra foram devolvidas aos seus proprietários originais, com exceção de poucos casos.

${ }^{32}$ Cf. M. Gallo, Historie de l'Espagne franquiste (Verviers, 1969), uma boa análise do dilema político que envolveu a adoção desta política.

33 34

${ }^{34}$ J. Esteban, op. cit., p. 84.

${ }^{35}$ Isto está muito bem documentado em Spain (World Bank Report/International Bank for Reconstruction and Development, 1963). 
Franco não resistiu necessariamente a todo tipo de mudança - ele apenas não quis perpetuar uma situação da década de 1930. Em conseqüência fez mudanças, mas num sentido que reduzisse ao mínimo a instabilidade de sua própria posição. Para atingir isto, se baseou num controle político muito rígido da economia.

\section{3. $\mathrm{O}$ governo autárquico}

Ao identificar-se intimamente com tradicionais idéias católicas, o governo autárquico espanhol representava um resíduo de ideologia conservadora, que relacionava o desenvolvimento industrial com alguma forma de degeneração moral (em parte porque este tivera sua expressão sistemática no liberalismo). Apesar de representar interesses políticos e econômicos de grupos muito fortes, o governo autár quico representava, como vimos, uma necessidade econômica em função do isolamento externo. Os dois países que apoiavam abertamente a situação política espanhola - Argentina e Portugal (ambos dominados nesta época por ditaduras) - tinham pouca importância econômica e portanto contribuíram pouco para estimular o crescimento industrial interno da Espanha via ampliação do seu comércio. Como resultado o desenvolvimento industrial sofreu nas décadas de 1940/50 retrocessos adicionais aos causados pelos problemas materiais e demográficos decorrentes da guerra civil. Uma combinação de fatores reduziu assim a posição de barganha e de poder nacional da elite industrial.

Os recursos de poder - tanto a nível local quanto a nível nacional continuavam na metade da década de 1950 firmemente nas mãos daqueles grupos que haviam dado forma ao tradicional Estado autoritário posterior à guerra $^{36}$. Em certo sentido a ideologia do Estado ainda reconhecia as aspirações de grupos industriais e empresariais, mas ao mesmo tempo procurava contê-las. Como resultado não se tentou nenhuma industrialização acelerada durante a primeira década depois da guerra. A produção agrícola foi favorecida em detrimento da produção industrial e o controle rígido do Estado sobre 0 desenvolvimento industrial através do INI não fomentou nenhuma indústria nova. Entrementes banqueiros e burocratas, bem como latifundiários, continuaram a beneficiar-se com o regime, graças ao seu controle sobre os recursos que administravam e o favoritismo das elites militares ${ }^{37}$. Mas Franco parecia consciente do perigo potencial embutido no fato de ignorar os interesses industriais. A alienação de tais grupos em relação ao sistema político numa si-

\footnotetext{
${ }^{36} \mathrm{~K}$. Medhurst, op. cit. , cap. 8.

${ }^{37}$ M. Gallo, op. cit.
} 
tuação como a da Espanha, onde os grupos em grande parte se sobrepunham ou podiam aglutinar-se ao longo de clivagens partidárias, classistas e lingüístico-culturais, não só dificultaria a convivência política, mas poderia facilmente tornar problemática a própria estabilidade ${ }^{38}$. Em essência foi isto que transformou o nacionalismo catalão, e mais tarde o basco, em um assunto tão relevante. Mas este aspecto deve ser visto como um problema mais amplo de integração, que afetou a Espanha pós-guerra civil e que se acentuou com o ressurgimento gradual da atividade indstrial em muitas áreas geograficamente periféricas do país.

A centralização politica e o rigido controle que o Estado mantinha sobre a estrutura político-administrativa local também reduziu as aspirações separatistas dos catalães. Mais: em torno de 1950 muitas das idiossincrasias da política local e a possibilidade de uma política pessoal em acordo com interesses privados tinham sido minadas pela transmissão e penetração mais efe tiva da estrutura burocrática no governo local e regional. Isto era especialmente importante para as áreas rurais mais remotas, onde no passado se vivia a relativa ineficácia e/ou indiferença para com as vicissitudes do governo central, o que permitia o controle político por parte da elite local sem interferência de fora.

O conjunto de "vasos não-comerciantes" que caracterizavam a Espanha no passado foi rompido. As transformações burocráticas não destruíram a estrutura do caciquismo e da patronagem no sul, mas, ao encorajar sua institucionalização, deram origem a uma série de hierarquias oficiais e semi-oficiais que refletia a ideologia do governo central ${ }^{39}$. No início (após a guerra civil) a preocupação com a estabilidade e a preservação do status quo eram compartilhadas pelas antigas elites rurais que manipulavam a estrutura e pelas forças "conservadoras" do governo central - sendo que este último em grande parte era composto por aquelas. Mas no final da década de 1950 e início da de 1960 a mudança de orientação na política nacional indicou a diminuição da habilidade do primeiro grupo para influir nas decisões, com um crescimento simultâneo de uma burocracia autônoma ${ }^{40}$. Ao julgar que sua influência nacional estava sendo colocada em xeque pelas concessões crescentes aos industriais da periferia, os latifundiários começaram a temer por suas posições na hierarquia local, que eles haviam dominado com tanto sucesso por mais de um século - mas com o apoio institucional do governo. Um esforço integrado pe-

${ }^{38}$ R.E. Dowse and J.A. Hughes, Political Sociology (London, 1972), pp. 130-134.

${ }^{39} \mathrm{Um}$ aspecto desenvolvido de forma convincente por O. Pi-Sunyer, "Elites and noncorporate groups in the European Mediterranean: a reconsideration ot the catalan case", in Comparative Studies in Society and History, pp. 117-131.

Medhu rst, op. cit., pp. 181-230. 
la industrialização diminuiria claramente o poder nacional das elites rurais, ainda mais que a política tenderia para uma acomodação dos interesses industriais. Ao reconhecer que seus interesses a longo prazo eram incompatíveis com os interesses da industrialização, eles perceberam que tal evolução minaria a estabilidade da estrutura agrária.

Mais uma vez muitos destes assuntos estavam ligados ao problema mais amplo da integraçðo, no sentido de que os objetivos nacionalistas do governo para consolidar sua posição significavam enfrentar os problemas de integração e de acumulação de capital. Mas estas políticas eram montadas dentro de uma estrutura com limitado crescimento sócio-econômico via planejamento, onde se faziam concessðes aos industriais periféricos em função do reconhecimento da necessidade de desenvolvimento industrial interno (concessðes que começaram a ser feitas a partir do aumento das contradiçðes entre uma estrutura política dominada em grande parte por interesses agrário-burocráticos e um setor econômico no qual os grupos industriais iam conquistando cada vez mais poder e influência). Além disso parecia crescer a incompatibilidade entre a autoridade tradicional dos proprietários rurais e os dirigentes burocrático-estatais. Mas isto era muito mais do que um simples conflito rural/urbano. Era algo semelhante à dissenção que existia entre centro e periferia na política nos anos anteriores à guerra, quando pela primeira vez se manifestou o nacionalismo catalão. Mas na década de 1950 as clivagens se tornaram evidentes, quando ambos os setores (dominados respectivamente por industriais catalães e latifundiários andaluzes) foram se distanciando cada vez mais no seu relacionamento estrutural: um de acordo com um sistema urbano industrial (capital-intensivo, divisão do trabalho derivada do uso de tecnologia, operariado semialfabetizado e uma crescente classe média), o outro mais ligado a uma estrutura agrária "autoritária tradicional" (trabalho-intensiva, hierarquia rigidamente estruturada, classe média restrita, composta por administradores e comerciantes). Os interesses próprios dos burocratas, tanto os do governo central quanto os dos governos locais sempre estiveram frouxamente articulados e se pautavam amplamente pelo respectivo grupo dominante (isto é, os latifundiários na Andaluzia e os industriais na Catalunha). Mas nas décadas posteriores à guerra foram capazes de firmar cada vez mais suas capacidades autônomas como grupo (não redutíveis aos meios de produção) a nível nacional e embora sujeitos em vários graus à "aprovação" permanente de Franco, foram construindo um aparelho de Estado centralizado, racional, burocraticamente administrado. $\mathrm{O}$ fortalecimento político do Estado central sob Franco representou um claro incentivo para a transição em direção a uma operacionalização autônoma, livre dos excessos da manipulação por parte dos interesses locais $^{41}$.

${ }^{41}$ S. Giner, op. cit., p. 63. 
Ao destruir muitos dos padrões sistemáticos e informais da ação político-administrativa dos latifundiários, uma importante dimensão do controle latifundiario sobre os assuntos rurais foi eliminada. No início tal per da não foi claramente percebida pelos latifundiários, ainda mais que a ideologia oficial e a política do governo central ainda sintonizavam com os interesses dos proprietários agrícolas (decisões do govemo central em favor dos interesses rurais). No entanto, quando tais políticas foram se deslocando cada vez mais no sentido de, na década de 1960, acomodar os interesses industriais, os "altos funcionários" ${ }^{42}$ apareceram como grupo muito forte em muitas áreas. Isto era importante em relação aos assuntos agrários, porque os proprietários foram obrigados a recorrer cada vez mais à negociação para terem atendidos os interesses e as necessidades que no passado eles próprios supriam de forma automática.

\section{O rompimento com o governo autárquico e o desenvolvimento de um Estado-Nação urbano-industrial-burocrático}

A intransigência política das classes superiores e dos dirigentes estatais era claramente visível até o final dos anos 1950, assim que a política nacional sempre foi restritiva. A estrutura econômica do país mudara pouco; o clima político era de repressão; e do ponto de vista social a maioria da população só pouco antes atingia níveis de vida iguais aos atingidos no começo da década de 1930. No entanto o regime franquista da década de 1940 não erradicara totalmente as clivagens anteriores à guerra. $\mathrm{O}$ nordeste industrializado mantivera um constante crescimento dentro desta estrutura nacional de restrição e de governo autárquico, enquanto as regiōes sul e central (com exceção de Madri e arredores) se mantinham predominantemente agrárias. Como resultado, a tentativa de unir as várias elites à sombra da ideologia do governo autárquico falhou, porque a natureza dos interesses destes grupos era muito diversificada. O Estado agrário-burocrático era totalmente incapaz de acomodar os interesses dos grupos industrial e comercial. Estes últimos tinham falhado em suas tentativas anteriores à guerra de negociar um caminho próprio para uma sociedade industrial de massas e se concentravam agora no desenvolvimento do setor industrial dentro de um processo de mudança centralmente planeja$d^{43}$. As contradições decorrentes de tais esforços vieram à tona no final da década de 1950. Este é o período que marca a transição da Espanha para um

${ }^{42} \mathrm{~K}$. Medhurst, "The political pressure of the Spanish bureaucracy", in Government and Opposition, 4(1969)2, p. 236.

${ }^{43}$ C.W. Anderson, The Political Economy of Modern Spain (Madisson, 1970). 
Estado-Nação urbano-industrial-burocrático moderno e o conseqüente rompimento com a política autárquica, favorável a interesses pré-industriais e ultra conservadores. São estes aspectos que serão destacados na discussão que segue.

Em primeiro lugar, o sistema sócio-econômico do governo autárquico era inerentemente instável, devido às contradiçðes entre grupos agrários e burgueses. Em segundo lugar, um alto nível de exploração da classe operária, estagnação persistente (sobretudo em função de uma tendência ao monopólio em quase todos os setores industriais) e intervenção estatal permanente no processo econômico fizeram com que a Espanha se encontrasse numa eterna crise econômica durante o começo da década de $1950^{44}$. Em terceiro lugar, sob a tutela de Franco um corpo burocrático foi capaz de consolidar sua posição e adquirir uma independência relativa em relação aos grupos dominantes da sociedade. Como conseqüência, esta burocracia foi capaz de articular seus interesses profissionais, sem precisar representar abertamente outros interesses. A necessidade de estimular a economia e o reconhecimento de Franco e dos executores da política de que o governo autárquico entrara em colapso, conduziu no final dos anos $50(1958 / 59)$ a uma modificação da ideologia oficial espanhola em direção a uma maior aceitação do desenvolvimento industrial nacional.

Em 1957 uma nova equipe de tecnocratas (o Opus Dei $)^{45}$, recrutados entre profissionais liberais e homens de negócio, assumiu posições-chaves no governo e pelo decreto de 25 de fevereiro os ministérios ligados à política econômica foram reunidos num comitê e criado o Departamento de Coordenação econômica e de Planejamento. Franco proclamou uma nova era em que "tradição" seria substituída por "racionalismo". Apesar de o planejamento do desenvolvimento nacional que se estendeu pelas décadas de 1960/70 ter representado uma evolução natural da influência industrial e tecnológica dentro dos grupos dominantes, sua legitimação temporária veio de forças externas, da OECD e do Banco Mundial. Ambos enfatizaram que se a Espanha quisesse prosperar "deveria acabar com o medo do mercado, desmantelar o aparelho ortopédico do governo autár quico e abrir o país ao comércio e ao investimento estrangeiros",46.

Os principais elementos da nova política podem ser resumidos da seguinte forma: a) ortodoxia na administração do setor público; b) economia

${ }^{44}$ Esteban, op. cit., p. 90.

${ }^{45} \mathrm{~L}$. Mackenzie, "The political ideas of the Opus Dei in Spain", in Government and Opposition, 1973, pp. 72-92; W. Ebenstein, Church and State in Franco Spain (Princeton, 1960), pp. 34-44.

${ }^{46}$ Carr, Fusi, op. cit., p. 54. 
aberta, em oposição ao governo autárquico; c) mercado livre, em oposição ao intervencionismo; d) investimento privado, em oposição ao estatismo ${ }^{47}$.

Esta mudança foi importante para a evolução mais recente da sociedade espanhola. Mas mais uma vez, apesar de que se fez uma investida material em direção à modernização, ela foi concebida dentro de um quadro político que representava um legado ideológico do governo autárquico da década de $40^{48}$. O sistema político permaneceu em essência o mesmo, mas muitos dos traços econômicos da sociedade mudaram. Na tentativa de conciliar interesses divergentes em uma situação potencialmente conflitiva, foram lançadas as sementes para um outro confronto. Como diz Esteban,

"os interesses da classe operária e de amplos setores de industriais e banqueiros pareciam coincidir agora na necessidade por liberdades democráticas que não podiam ser toleradas pela ditadura de Franco, com a qual sindicatos e liberdade política eram incompatíveis" ${ }^{, 49}$.

O que importa é que muitas das mudanças materiais provocaram reações em outras áreas e setores da sociedade que com o tempo minaram a estabilidade de grupos que em certa medida contribuíram para a manutenção do governo autárquico. Este processo foi importante, sobretudo na Andaluzia, onde as mudanças durante o final da década de 1950 e na de 1960 tinham tido efeitos profundos sobre o equilíbrio do poder político nacional.

\section{A transformação das estruturas agrárias}

Nas primeiras décadas depois da guerra a urbanização e em menor grau também a industrialização eram evidentes no sul, mas as estruturas sócio-econômicas das áreas rurais continuavam imersas numa estrutura de autoritarismo, subdesenvolvimento e pobreza ${ }^{50}$. A estrutura das relações sócio-econômicas, a configuração e as instituições do poder político, bem como o aparelho da autoridade provincial, permaneciam solidamente nas mãos de uma pequena

${ }^{47} \mathrm{Cf}$. discursos de M. Arbura (Ministro do Comércio) reunidos em Cinco Años al Frente del Ministerio de Comercio (Madrid, 1950).

48

49

${ }^{50}$ Esta situação é confirmada por muitos autores. Cf. J. Martinez Alier, Labourers and Landowners in southern Spain (London, 1971); A. C. Comin, Noticia de Andalucia (Madrid, 1970), pp. 39-53; N. Salas, Andalucia (Barcelona, 1972). 
elite rural $^{51}$. Em vista disso a possibilidade relativa de acesso a posições de poder era extremamente limitada. Um estrato de empresários em formação havia surgido, com um status bem mais elevado em regiões como a Andaluzia, onde no passado haviam brilhado pela ausência ou nunca tinham exercido qualquer papel dinâmico entre a elite local ${ }^{52}$. No entanto, seu peso antes de 1950 era limitado. Mas mesmo nos estágios iniciais de seu crescimento numérico constituíam um grupo significativo, representando uma geração neocapitalista que se distinguia dos industriais conservadores de classe alta, que se podia encontrar nas regiðes industriais após a guerra. Antes do final dos anos 50 a falta de apoio institucional para atividades comerciais dinâmicas na verdade barrou o poder destes grupos ${ }^{53}$. Como conseqüência, não conseguiram estimular o surgimento de um estrato de pequenos proprietários rurais ricos, para competir com os latifundiários das áreas agrícolas.

As mudanças estruturais durante o século XIX impediram o desenvolvimento deste grupo, enquanto a proposta de reforma agrária da Segunda República, que nunca foi posta em prática em função da hegemonia política dos latifundiários, constituiu um outro motivo de retrocesso. Mudanças eram improváveis, enquanto o Estado continuasse a proteger os interesses dos grandes proprietários. A estrutura da sociedade rural espanhola só foi modificada por uma série de acontecimentos e grupos que eram externos e relativamente independentes em relação às classes rurais superiores.

A discussão anterior mostrou as peculiaridades da luta regional entre diferentes estruturas sócio-econômicas nas décadas posteriores à guerra. Como resultado muitos dos impulsos decorrentes da expansão industrial e comercial vieram das áreas periféricas do norte. Ao menos esta era a situação até o início da década de 1950. A partir de então, no entanto, a urbanização, a migração, o crescimento industrial e os primeiros estágios do boom turístico estimularam o aparecimento de grupos locais mais dinâmicos, que tinham interesse em modificar o interior da Andaluzia. Eles foram auxiliados na sua obtenção de um status maior pela íntima associação com grupos tecnocráticos, cuja influência e participação na burocracia estatal estava aumentando cada vez mais desde $1957^{54}$.

$\mathrm{O}$ esforço em manter a estabilidade dentro de um esquema de mudança centralmente planejado provocou a estagnação, mas uma postura destas mos-

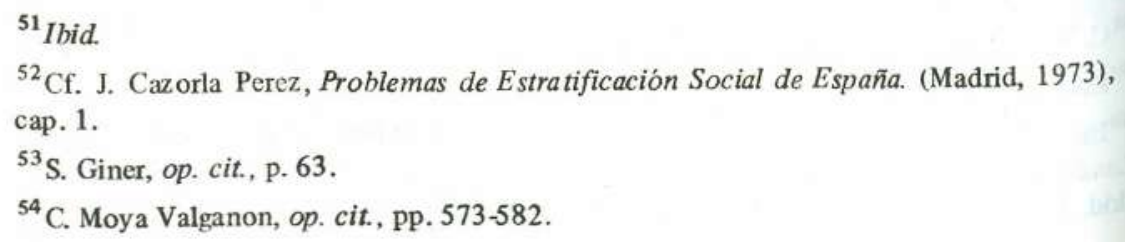
cap. 1 .

${ }^{53}$ S. Giner, op. cit., p. 63.

${ }^{54}$ C. Moya Valganon, op. cit., pp. 573-582. 
trou-se impraticável e impossível a longo prazo. Isso era temporariamente possível por causa do isolamento em relação ao resto da Europa ocidental, em especial durante os anos de boom após a Segunda Guerra, quando a Europa em geral teve um considerável crescimento econômico. Mas, apesar do isolamento imposto como conseqüência do governo autárquico, certos setores da sociedade espanhola não puderam resistir a mudanças estruturais que aconteciam em decorrência do crescimento industrial em outros setores. Sobretudo o interior experimentou uma série de transformações que decorriam de um tal processo mais geral de mudança que estava em andamento no restante da Espanha e no noroeste da Europa. Em rápidos traços estes processos podem ser descritos como segue.

Cada vez mais gente estava deixando as áreas rurais, procurando trabatho nas cidades e áreas industriais do nordeste - e nos anos 60 o grande fluxo de emigrantes para o noroeste da Europa. Inicialmente sua partida apenas diminuiu a pressão sobre a terra, que o crescimento demográfico das décadas anteriores causara. Mas na segunda metade da década de 60 e em anos recentes muitos dos proprietários de terra (especialmente os latifundiários) foram obrigados a elevar os salários e a encontrar recursos para mecanizar a agricultura $^{55}$. As condições sociais em muitas áreas rurais se desenvolveram muito em função destas mudanças e, apesar de que ainda não existe em larga escala uma classe média de pequenos proprietários, a agricultura de subsistência que dominava as áreas de latifúndio (leste da Andaluzia) desapareceu em grande parte, consolidando-se as pequenas parcelas de terra ${ }^{56}$. Tais mudanças representam um abandono dos métodos de mão-de-obra intensiva e repercutem nas relações de produção no setor rural.

As áreas urbanas também conseguiram desvenciliar-se da influência da estrutura rural autoritária na Andaluzia. Isto se devia em parte à influência $\mathrm{e}$ à consolidação de um grupo empresarial, cujos interesses e cujo aumento de status estava intimamente ligado à expansão comercial e industrial nas áreas urbanas $^{57}$. Uma explicação adicional pode ser buscada na reorientação gradual da política nacional e no rompimento com o governo autárquico acima mencionado ${ }^{58}$. A centralização crescente e a maior eficiência da estrutura po-

${ }_{55}^{5}$ J. Martinez Alier, op. cit., pp. 49-90.

${ }^{56}$ Houve muitas políticas oficiais em relação à consoli dação da terra, mas mudanças significativas ocorreram nestas áreas independente destas diretrizes. Isto resultou das mudanças estruturais gerais que ocorrem em muitas áreas rurais. As diretrizes oficiais (e sua base ideológica) podem ser entendidas através de um exame das informações fornecidas pelo Instituto Nacional de Colonisación (INC), em especial Plan de Badajoz (Madrid, 1966).

${ }^{57}$ R. Herr, Spain (Englewood Cliffs, 1971), pp. 236-261.

${ }^{58}$ Ibid. 
lítica facilitou uma maior disseminação da ideologia franquista, a qual, combinada com o aumento da alfabetização e dos meios de comunicação de massa, conseguiu penetrar com sucesso no interior ${ }^{59}$. Isto também significou que muitos dos "compartimentos" regionais foram rompidos e integrados no desenvolvimento de um moderno Estado burocrático. As velhas "classes médias" ainda existiam em áreas urbanas e no interior, mas os membros especializados e profissionais liberais da nova classe média, juntamente com o estrato empresarial já citado, estavam preocupados em romper as relações tradicionais e "vínculos" informais que sustentavam este grupo. Com isto adquiririam maior influência sobre a máquina político-administrativa local e tornariam a estrutura de mercado das áreas rurais mais competitiva.

O proletariado industrial que se expandira gradualmente desde o século XIX, aumentou consideravelmente (sobretudo via imigração vinda do sul) em função do desenvolvimento sustentado que ocorreu no final da década de $1950^{56}$. É improtante que estas mudanças não se restringiam às áreas periféricas com sua longa tradição em empreendimentos industriais. A expansão comercial e industrial nas áreas urbanas pelo país afora - incluindo muitas das cidades andaluzas das províncias ocidentais - também representou a expansão constante de oportunidades de emprego na indústria e nos serviços. No final da década de 50 a Espanha apresentava sinais de diminuição na força de trabalho dominada pela agricultura e passava a ter uma estrutura ocupacional que se que se assemelhava a um Estado-Nação industrial. Além disso se assistia a uma transformação das relações agrárias, com conseqüentes mudanças na composição de classes e nas relações de produção.

$\mathrm{O}$ que é importante além de tudo isto nesta década pós-guerra é o fato de que, apesar de ela ter sido caracterizada como era de limitação, de repressão e de autarquia ecorıômico/política, havia grupos que se mantiveram unidos dentro de uma estrutura pouco rígida e muitas vezes conflitiva na administração da política econômica e que estimularam o desenvolvimento futuro. $\mathrm{O}$ isolamento da Espanha em relação ao resto do mundo durante este período representou - não obstante as atividades do INI - um incentivo de longo prazo para um crescimento industrial autóctone mais dinâmico, não muito ligado

\footnotetext{
${ }^{59} \mathrm{~A}$ criação e a instalação pública de muitas instituições creditícias podem ser vistas como tentativa do governo nacional para promover uma exploração comercial mais rigorosa da agricultura. Tais agências, como o Serviço Nacional de Crédito Agrícola (1946), transformado depois em Banco Nacional de Crédito Agrí́cola (1962) reflete a tentativa de estimular os grupos embrionários de produtores médios, sobretudo no sul. O crescimento urbano e a conquista de mercados mais amplos (via agilização dos transportes) nos anos posteriores à guerra eram vistos como ou tros estímulos a estas iniciativas.
}

${ }^{60}$ R. Tamames, op. cit. 
a características e estruturas regionais. A política de centralização de Franco visava anular quaisquer sentimentos que grupos periféricos porventura nutriam. Ela tảmbém criou um esquema - como já foi visto - para uma integração funcional dos grupos (e das estruturas) da heterogênea Espanha.

Pelo final da década de 50 o esforço tecnocrático dos dirigentes estatais era muito evidente. Como um grupo cada vez mais autônomo eles conseguiram manipular uma situação em que a posição das forças conservadoras na sociedade (especialmente dos latifundiários) se tornava cada vez mais problemática e insegura. Isto era um resultado da migração crescente vinda das áreas rurais, bem como da crescente incompatibilidade entre seus interesses de longo prazo e os da Espanha como um todo. Apesar de que as mudanças desde a guerra civil e até 1957 eram graduais e planejadas, provocaram uma reação em cadeia em setores da sociedade (sobretudo das áreas rurais) que tinham permanecido imunes aos impactos iniciais destas mudanças.

A partir de 1950 os grupos empresariais e os profissionais de classe média passaram a perseguir cada vez mais objetivos que estavam mais em sintonia com uma Espanha industrializada e mais distanciados do sentimento de opressão e "ruralidade" que caracterizava a região até então ${ }^{61}$. Isto era facilitado pelo amálgama ideológico da "tecnocracia", alimentada por administradores estatais que, juntamente com Franco, enxergavam a estabilidade futura numa crescente capacidade de produção e numa expansão da sociedade de consumo.

No período a partir das mudanças de gabinete ocorridas em 1957 ficou cada vez mais evidente que as diversas manifestaçōes de autarquia eram incapazes de impedir que partes da Espanha se encaminhassem para uma direção determinada pelas mudanças estruturais provocadas pela industrialização e pelo crescimento industrial ${ }^{62}$. A aceitação do "liberalismo econômico" (capitalismo alinhado com a Europa ocidental e os Estados Unidos) resultava em parte de uma série de profundas crises econômicas, bem como do reconhecimento do aumento de status dos grupos empresariais na sociedade.

A ideologia de opressão e de austeridade tornava-se inviável diante de uma Espanha que sofria os efeitos das contradições internas. Diante da burocracia estatal cada vez mais orientada numa linha tecnocrática (e obtendo legitimidade política e coesão através do Opus Dei) os grupos industriais e comerciais menos conservadores foram capazes de convencer Franco. $\mathrm{Na}$ linha de uma política oficial de crescimento verificou-se que os interesses industriais se tornavam cada vez mais aptos a negociar seus objetivos de um esforço nacio-

\footnotetext{
${ }^{61}$ Ignacio Fernández de Castro e A, Goytre, Clases Sociales en España en el Umbral de los años '70' (Madrid, 1974), pp. 164-168.

${ }^{62}$ Herr, op. cit.
} 
nal de industrialização e assim abandonar (ou ao menos diluir) seus sentimentos separatistas. Até os grupos conservadores reconheceram o fracasso de sua política autárquica ou ao menos a repensaram à luz das mudanças que eram evidentes.

As mudanças estruturais nas cidades sulinas, até então dominadas por estruturas agrárias, tornaram-se cada vez mais claras sobretudo porque a politica que unia as classes superiores desde a guerra civil estava aumentando cada vez mais o problema da estagnação econômica, em vez de reduzi-lo. Era evidente que, se tais grupos quisessem manter sua posição de influência, deveriam acomodar-se às mudanças inevitáveis, em vez de suprimi-las. No passado eles tinham resistido com relativo sucesso à incursão de idéias, relaçðes e técnicas capitalistas, que poderiam ter transformado a produção agrícola ${ }^{63}$. Os latifundiários sempre tiveram razoáveis margens de lucro, mas o problema agora se localizava nos mecanismos mais gerais, dentro dos quais esta estrutura sócio-política se enquadrava ${ }^{64}$.

O controle efetivo sobre os recursos locais era uma das pedras angulares da estrutura agrária. Juntamente com a estrutura político-administrativa relativamente descentralizada e o sistema de patronagem, o aparelho de poder estava firmemente nas mãos de uma pequena, mas influente elite autoritária. Os esquemas de controle econômico, político e social estavam praticamente nas mãos das mesmas pessoas e qualquer acesso por parte de outros grupos a estruturas de instâncias locais de decisão era conseqüentemente muito limitado. As mudanças embrionárias anteriores a 1957 e as que foram postas em prática depois desta data minaram, no entanto, esta autocracia regional. A elite hegemônica do interior, especialmente da Andaluzia, era o grupo para quem tais mudanças se tornavam especialmente problemáticas. A transferência para objetivos tecnocráticos se refletira na perda de apoio institucional para os grandes proprietários por parte do governo nacional. Isto por sua vez aceleraria as mudanças que estavam destruindo a estrutura da sociedade rural, forçando os adeptos da experiência autárquica e firmar um compromisso com as forças de uma Espanha com uma indústria emergente. A década de 60 testemunhou a materialização deste fato.

${ }^{63}$ Cf. M. Signan Soler, "Nueva Teoria de Andalucia", in Revista de Estudios Agro-Sociales, 69/1969, pp. 13-18.

${ }^{64}$ J. Martínez Alier, op. cit., pp. 88-91. 


\section{Conclusão}

A discussão acima evidenciou alguns pontos. Primeiro, as mudanças na configuração dos grupos dominantes e suas relações modificadas em relação aos meios de produção mostram as complexas dimensões estruturais subjacentes ao desenvolvimento espanhol da guerra civil. Segundo, estas mudanças estruturais assumiram formas meio labirínticas em função de clivagens étnicas e lingüísticas. Terceiro, ampliou-se uma burocracia autônoma, inicialmente sob a tutela cuidadosa de Franco e com grande participação de pessoal militar indispensável para manter a ordem e o controle sobre a sociedade -, mas depois cada vez mais independente. Quarto, Franco foi muito hábil em manipular os acontecimentos e as transformaçðes, mantendo o controle através de um apoio militar nunca questionado. Ao refazer, em 1957, sua antiga orientação autocrática, estava apenas pondo em prática sua sagacidade política e uma consciência pragmática das realidades estruturais em mudança. Sob muitos aspectos ele permaneceu como árbitro final das mudanças e dos acontecimentos externos e internos.

Se alguém vê o Estado como um complexo sistema institucional no qual a natureza e a extensão da influência das classes depende da forma de sua organização e de suas alianças, a questão da autonomia do Estado pode facilmente ser complicada por uma ênfase demasiada sobre as funções arbitrais da burocracia. Para evitar isto é preciso reconhecer a distinção - muitas vezes sutil - entre autonomia do Estado e uma burocracia estatal, cuja possibilidade de tomar decisões autônomas pode variar de acordo com os diferentes contextos institucionais. Esta é uma distinção importante, porque permite avaliar o exercício da tomada de decisões por parte de dirigentes estatais no contexto de configurações de classe em mudança, sem reduzi-lo a um instrumento passivo destas classes. Ao mesmo tempo reconhece que autonomia burocrática não surge de forma sui generis.

No caso da Espanha dirigentes estatais, que antes da guerra vinculavam seus interesses na preservação do poder aos interesses das tradicionais classes superiores (latifundiários, banqueiros, militares, clero), encontraram o vácuo político posterior à guerra e este foi muito apropriado para a consolidação da sua autonomia em relação à dependência anterior. Apesar do fato de que as diretivas políticas muitas vezes tinham sua origem na visão que Franco tinha do futuro da Espanha, o ditador reforçou o aparelho burocrático da administração estatal, dotando tais instituições, se não com legitimidade popular, ao menos com os meios políticos e econômicos para uma ação incisiva. As reformas de 1957 apenas institucionalizaram a ideologia tecnocrática esposada pelos administradores estatais e como tais podem ser vistas como produto lógico de sua tentativa de lidar de forma independente com os problemas estruturais 
que pesavam sobre a economia espanhola submetida à autocracia. Se a guerra civil abriu a possibilidade para uma centralização e consolidação burocrática, as mudanças estruturais do pós-guerra facilitaram o aumento de sua autonomia. Este aumento da autonomia pode ser visto em duas fases distintas.

Na primeira fase (1939-1957) cresceu a autonomia burocrática em relação a grupos dominantes e os meios de produção começaram a desenvolver-se, mesmo que ainda sob a orientação de Franco e por meio de uma estreita aliança com os militares, o que fazia com que burocracia e militares fossem em grande parte sinônimos. Na segunda fase (1957-1975) a autonomia passou por uma modificação, mesmo que o sustentáculo militar permanecesse forte.

$\mathrm{O}$ que torna o caso da autonomia estatal na Espnha problemático e intrigante, não é o crescimento de uma burocracia relativamente autônoma nem a persistência de mudanças estruturais internas nem os acontecimentos internacionais fora do país, mas também o modo pelo qual um homem - Franco - foi capaz de mediar este processo e impor um caráter inconfundível ao autoritarismo corporativo que o acompanhava. Não há melhor ilustração para isso do que o caminho pelo qual a transição democrática e outros desdobramentos posteriores à sua morte foram encaminhados - isto se deu em grande parte graças à elasticidade de um aparelho burocrático autônomo, institucionalizado e crescentemente legitimado, montado por ele. Isto não é um simples adendo diante da natureza problemática e das expectativas contraditórias da transição. Além disso deve-se lembrar que os militares continuam a exercer o papel de guardiães políticos e como tais continuam, como no tempo de Franco, a ser os possíveis árbitros do futuro da Espanha. É a possibilidade de tal intervenção, percebida ou sugerida, que ironicamente ajudou a consolidar a legitimidade crescente da autoridade burocrática e como tal tem ajudado os esforços para um governo democrático.

*Traduzido do inglês por René E. Gertz (professor no Departamento de História da PUCRS). As referências bibliográficas estão reproduzidas na sistemática em que aparecem no original (N.T.).

* Departamento de Sociologia da Wake Forest University, Winston, NC. - U.S.A. 